\title{
Shewanella putrefaciens: A Rare Anaerobic Bacterium Mimicking Necrotizing Soft Tissue Infection
}

\author{
Abbasali Badami, Shachar Shimonovich,' Siara Kolpon,2 and Vladimir Rubinshteyn²
}

\begin{abstract}
Background: Shewanella putrefaciens, an anaerobic, gram-negative, iron-reducing bacterium found in marine environments, is described here as cause of septic shock and a rare type of soft tissue infection.

Case Presentation: We report a case of a 52-year-old female who presented to our facility with findings of altered mental status, septic shock, and right lower extremity swelling, redness, bullae formation, and erysipelas. Intra-operative evaluation was undertaken out of concern for necrotizing soft tissue infection, which was ruled out clinically. Prospective follow-up of intra-operative cultures showed evidence of marine pathogen Shewanella putrefaciens in the tissue culture and a cause of bacteremia.

Discussion: With only 255 cases reported in the literature since 1973, Shewanella putrefaciens is known for causing ear infections, abdominal, biliary tract infections, and rarely, soft tissue infections. Severe bacteremia with fulminant septic shock may develop in as much as $28 \%$ of patients. In our case, Shewanella infection mimicked necrotizing soft tissue infection in its clinical presentation and aggressive evolution. It is therefore prudent to be familiar with this rare pathogen as a cause of soft tissue infection and sepsis and to be able to differentiate it from necrotizing soft tissue infection.
\end{abstract}

Conclusion: Diligence in surgical site debridement and surgical site exploration are paramount in dictating patient care for these types of infections.

Keywords: necrotizing fasciitis; rare soft tissue infection; Shewanella putrefaciens

$\mathbf{F}$ ROM ITS DISCOVERY in 1931 and definition in medical literature in 1973, few cases of the uranium-reducing bacteria Shewanella putrefaciens have been described. The most recent case review study was performed nearly seven years ago by Cabié et al. [1,2]. Shewanella spp. is a gramnegative bacterium that is rarely pathogenic [3]. The bacterium lives in marine environments, is known to flourish and survive at $13^{\circ} \mathrm{C}$, and is found rarely in dairy products, oil, and carcasses [4]. Overall, more than 25 Shewanella species exist with only two known for their invasive nature toward a human host, Shewanella putrefaciens and Shewanella algae. Clinical symptoms examined and prevalent in the limited literature include otitis media, hepatobiliary infection, soft tissue infections, and worrisome bacteremia. Rarely, this organism has been linked to healthcare-associated infection and outbreaks associated with medical devices [5,6]. Infections with Shewanella mimicking necrotizing soft tissue infection are rare and having knowledge about its presenting history and presentation is crucial in defining role of surgical debridement versus infectious medical management. Our surgical team at a community hospital was faced with a case to be evaluated for surgical management of possible necrotizing soft tissue infection later diagnosed as Shewanella putrefaciens causing soft tissue infection.

\section{Case Presentation}

A 52-year-old female with past medical history of hypertension, spinal stenosis, anxiety, and polysubstance abuse taking suboxone presented to emergency department with

\footnotetext{
${ }^{1}$ Department of Surgery, SUNY Downstate Medical Center, Brooklyn, New York.

${ }^{2}$ Division of General Surgery-Department of Surgery, Richmond University Medical Center, Staten Island, New York.
}

(C) Abbasali Badami et al. 2017; Published by Mary Ann Liebert, Inc. This Open Access article is distributed under the terms of the Creative Commons License (http://creativecommons.org/licenses/by/4.0), which permits unrestricted use, distribution, and reproduction in any medium, provided the original work is properly credited. 


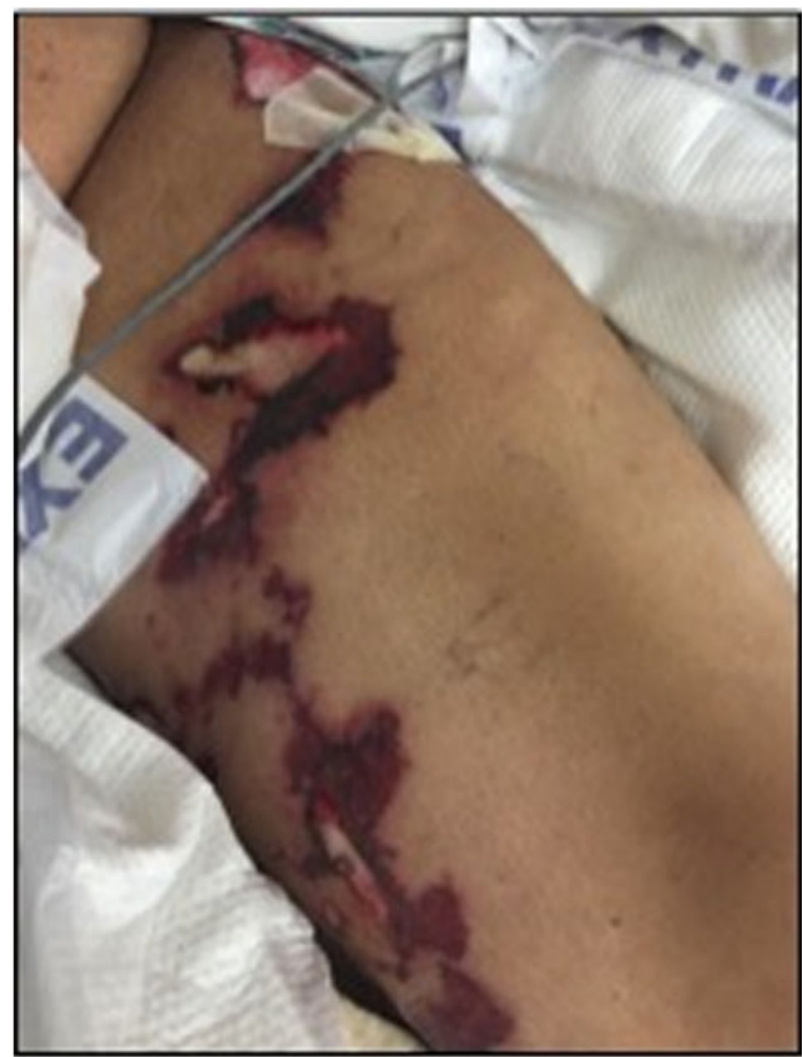

FIG. 1. Evidence of left thigh involvement with the disease.

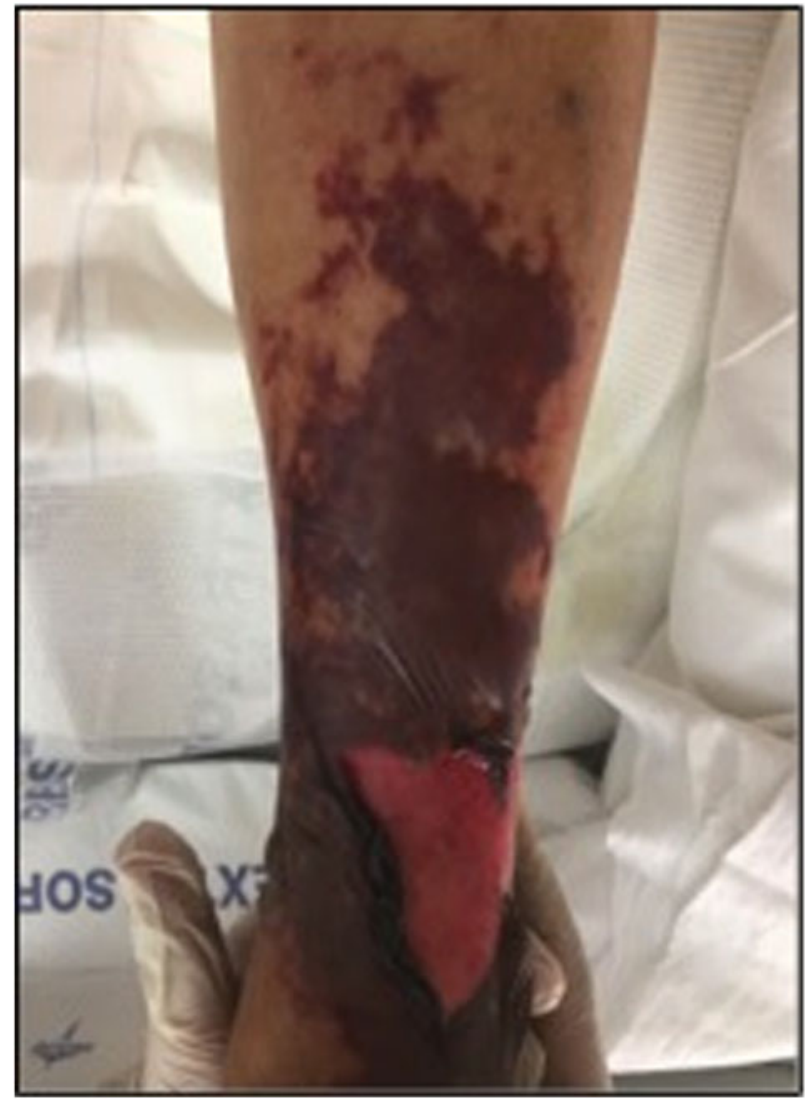

FIG. 2. Extensive bullae formation with rupture on the left lower extremity.

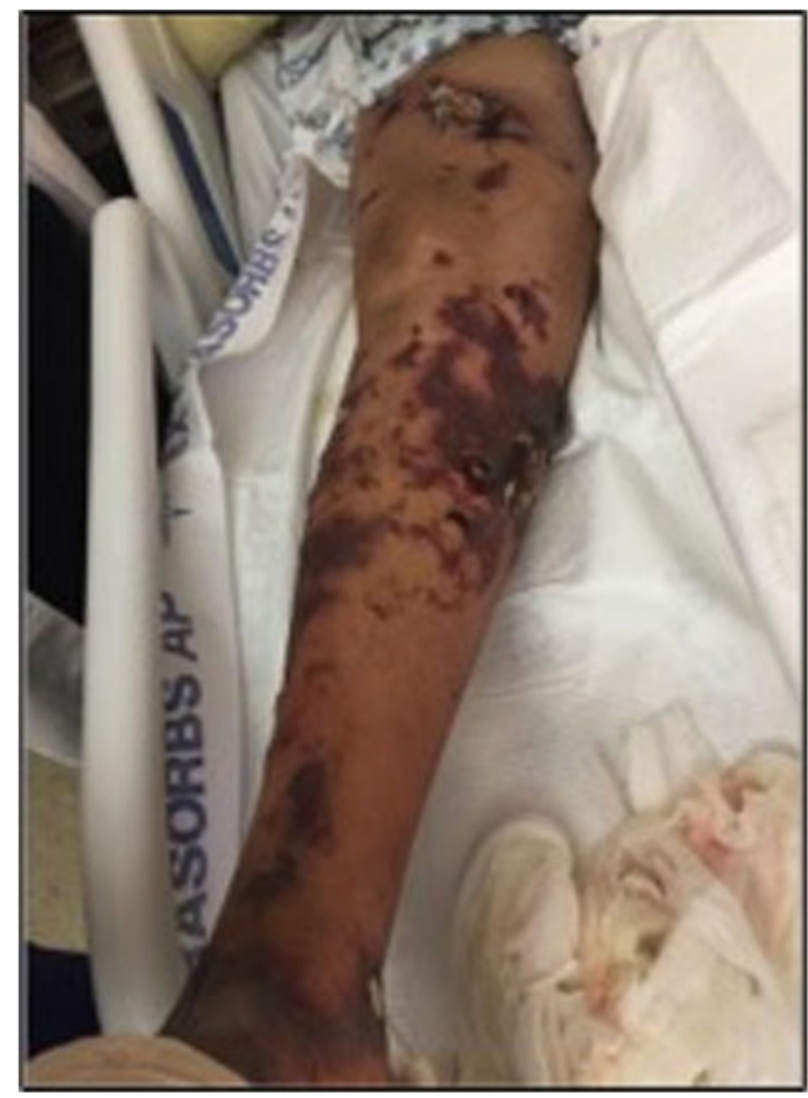

FIG. 3. Complete view of right lower extremity disease.

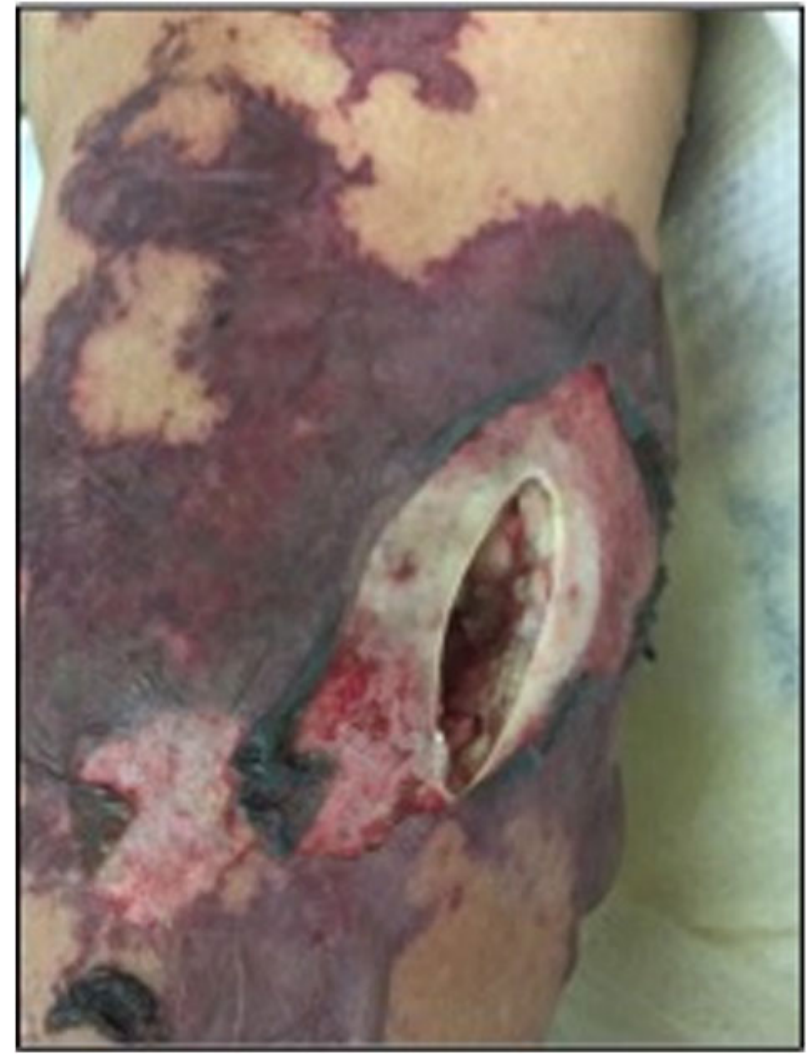

FIG. 4. Ruptured bullae with close-up view of right median calf fasciotomy incision. 


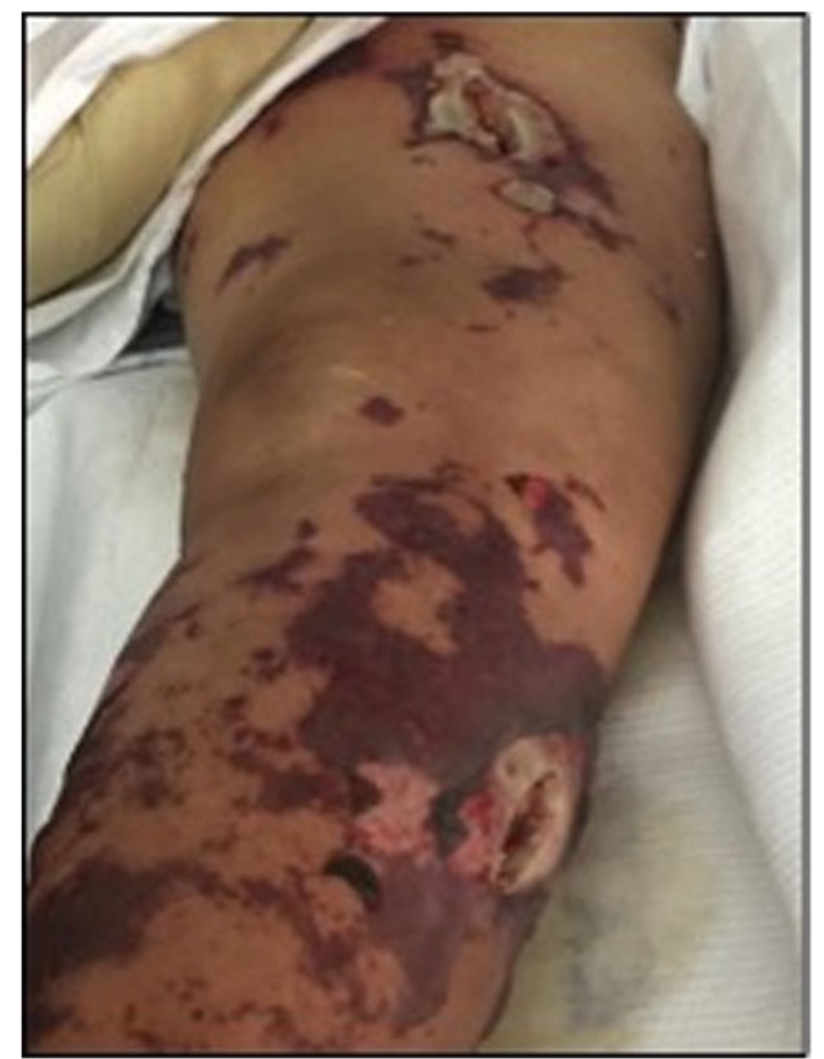

FIG. 5. Post-fasciotomy right lower extremity with erysipelas and bullae formation.

altered mental status. Initial evaluation in the emergency department elucidated findings consistent with septic shock, confusion, hypotension, and tachycardia. Furthermore, the patient presented with bilateral lower extremity swelling, redness, bullae formation, and erysipelas, which was worsening over a short period of time (Figs. 1 and 2). General surgery was consulted because of concerns for a necrotizing soft tissue infection. Limited history obtained from the patient indicated that she had had right lower extremity pain and swelling for four days, with associated bullae formation that had progressed. The patient also reported subjective fevers while at home. The patient denied any recent exotic travel history, although she did report a recent trip to Virginia where she consumed fresh crabmeat. While in the emergency department, the patient became hypotensive with systolic blood pressures in the 70s, was given norepinephrine, and transferred to the medical intensive care unit (ICU).

Surgical evaluation was highly suspicious for necrotizing soft tissue infection with an associated LRINEC score of 4, and the patient was taken to the operating room for lower extremity exploration and possible operative debridement. Three incisions, each approximately $4 \mathrm{~cm}$ in size were carried out in the medial thigh, anterior thigh, and medial calf (Figs. 3-6). Dissection was carried through to the fascial layer and the fascia was carefully exposed, evaluated, and opened to reveal the muscle layer. The skin and subcutaneous tissue were noted to be edematous, however, no evidence of necrotizing soft tissue infection was observed; fascia and muscle were viable. After surgical exploration, the patient remained

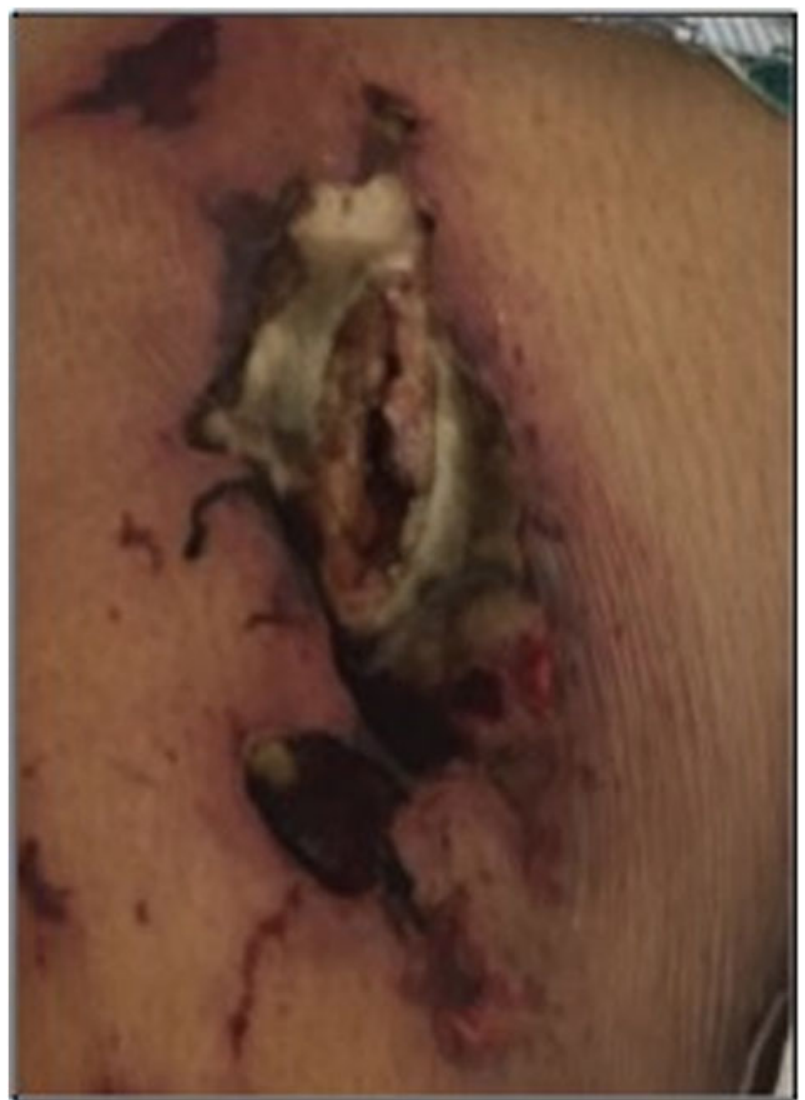

FIG. 6. Right thigh anterior fasciotomy incision.

in septic shock, requiring pressor and ventilatory support. Intra-operative surgical site cultures revealed Shewanella putrefaciens as the causative organism, and was confirmed as the source of bacteremia from blood cultures. The patient was given gentamicin $240 \mathrm{mg}$ every 24 hours and meropenem $1 \mathrm{~g}$ every 8 hours. At post-operative day 14, the patient was extubated and no longer on pressors after aggressive critical care management, although she remained critically ill. In our experience, severe sepsis caused by Shewanella putrefaciens appears to predispose patients to severe sepsis with long intensive care hospitalizations and significant morbidity.

\section{Discussion}

Shewanella putrefaciens appears to invade human hosts opportunistically in a limited number of cases, and is therefore a rare cause of bacteremia. Although the relatively low LRINEC score, clear signs of sepsis with expanding patches of erysipelas and bullae formation were highly suspicious and necessitated surgical exploration. Intra-operatively, the incisions were left open and packed, providing a continued window for evaluation of the lower extremity fascia and underlying muscle post-operatively. Despite the fact that Shewanella spp. infection is a rare cause of necrotizing soft tissue infection, the authors stand by the role of operative exploration of all rapidly expanding and worsening lower extremity infections. In severe sepsis, awaiting cultures speciation and sensitivity may only increase the tissue burden for debridement and unfavorably affect the patient's course. 
Therefore, early exploration, debridement, and surgical evaluation of Shewanella putrefaciens soft tissue infection may prevent delay of care, provide dependable site cultures, and provide a window into the underlying tissue to ensure that no progression of infection into the fascial planes takes place.

The patient's history is suggestive of an ingested source for her Shewanella spp. infection from ingested seafood. Limited literature exists to support an enteral mode of infection, although a case report exists attributing a Shewanella enteral infection from raw seafood to a severe bacteremia [7]. Our patient is only the second recorded patient in the literature that suffered from a Shewanella putrefaciens bacteremia secondary to ingestion of undercooked seafood, and the only one to manifest with severe bacteremia and soft tissue infection concomitantly. We feel that early operative exploration of a suspicious soft tissue infection was appropriate because it provided dependable cultures for speciation and sensitivities, provided a window for ongoing evaluation of the underlying tissue, dictating whether further operative intervention was warranted, and most importantly, ruled out the presence of a necrotizing soft tissue infection or a fasciitis.

Shewanella putrefaciens remains a rare cause of opportunistic infection in humans. In our case, however, this organism mimicked the findings of a necrotizing soft tissue infection, forcing operative exploration of the infected lower extremities.

\section{Author Disclosure Statement}

The authors declare that there is no conflict of interest.

\section{References}

1. Derby H, Hammer B. Bacteriology of butter. Part IV. Bacteriological studies on surface tainted butter. Iowa Agric Exp Stn Res Bull 1931;145:389-416.

2. Vignier N, Barreau M, Olive C, et al. Human infection with Shewanella putrefaciens and S. algae: Report of 16 cases in Martinique and review of the literature. Am J Trop Med Hyg 2013;89:151-156.
3. Vogel BF, Jorgensen K, Christensen H, et al. Differentiation of Shewanella putrefaciens and Shewanella alga on the basis of whole-cell protein profiles, ribotyping, phenotypic characterization, and 16S rRNA gene sequence analysis. Appl Environ Microbiol 1997;63:2189-2199.

4. Khashe S, Janda JM. Biochemical and pathogenic properties of Shewanella alga and Shewanella putrefaciens. J Clin Microbiol 1998;36:783-787.

5. Tsai MS, You HL, Tang YF, Liu JW. Shewanella soft tissue infection: Case report and literature review. Int J Infect Dis 2008;12:e119-e124.

6. Oh HS, Kum KA, Kim EC, et al. Outbreak of Shewanella algae and Shewanella putrefaciens infections caused by a shared measuring cup in a general surgery unit in Korea. Infect Control Hosp Epidemiol 2008;29:742-748.

7. Shimizu T, Matsumura Y. A case of bacteremia and suppurative vertebral osteomyelitis/discitis due to Shewanella algae occurring after raw-fish consumption. Kansenshogaku Zasshi 2009;83:553-556.

Address correspondence to: Dr. Abbasali Badami

Richmond University Medical Center 355 Bard Avenue Staten Island, NY 10310

E-mail: dr.badami@hotmail.com
Abbreviations Used
$\mathrm{ICU}=$ intensive care unit

Cite this article as: Badami A, Shimonovich S, Kolpon S, Rubinshteyn V. (2017) Shewanella putrefaciens: A rare anaerobic bacterium mimicking necrotizing soft tissue infection. Surgical Infections Case Reports 2:1, 88-91, DOI: $10.1089 /$ crsi.2017.0023 